\title{
HUMIC SUBSTANCES AS A POTENT BIOMATERIALS FOR THERAPEUTIC AND DRUG DELIVERY SYSTEM-A REVIEW
}

\author{
KALA K. JACOB ${ }^{1 *}$, PRASHOB PETER K. J. ${ }^{2}$, CHANDRAMOHANAKUMAR N. ${ }^{1}$
}

${ }^{1}$ Inter University Centre for Development of Marine Biotechnology, Cochin University of Science and Technology, Kerala, 682016 India, 2Department of Chemical Oceanography, Cochin University of Science and Technology, Kerala, 682016 India

Email: kalajacob@cusat.ac.in

Received: 16 Dec 2018, Revised and Accepted: 18 Mar 2019

\begin{abstract}
Efficiency of therapeutic compounds could be enhanced by encapsulation and covalent attachments to a biomaterial carrier. Complex formation with humic substances is valuable techniques to improve bioactivity of natural products. Fractal structures of humic substances also have adjacent carboxyl and hydroxyl groups. Along with molecular bonding property, reduction-oxidation and association-dissociation capacities of humic substances are considered this as a biomaterial for transform, other molecules, and substances. Immune system responses of humic acid stimulates in the human body. However, pharmaceutical importance of humic substances, demands on evidenced efficacy and a clearly defined chemical composition of the preparations used. Toxicological safety standards also have to be evaluated. This review summarises the application of humic substances as pharmaceuticaly important biomaterial. Research on this zone opened up an application for humic substances in pharmacogonasy.
\end{abstract}

Keywords: Humic substances, Biomaterial, Drug delivery, Humic acid, Fulvic acid

(C) 2019 The Authors. Published by Innovare Academic Sciences Pvt Ltd. This is an open access article under the CC BY license (http://creativecommons.org/licenses/by/4.0/) DOI: http://dx.doi.org/10.22159/ijap.2019v11i3.31421

\section{INTRODUCTION}

Search for bio-compatible and efficient drugs is a prime state-of theart requisite in drug development. In various drug combinations, biomaterials like fulvic and humic acid, augment solubility, permeability, and dissolution [1]. Greater patient compliance of drugs with ease drug dissolution and absorption profile can facilitate through combinations of potent biomaterial carrier in matrix formation [2]. Range of formulation components and processing methods can contribute significantly in the dissolution rate of pure drugs [3]. Broad regulatory acceptance, desirable drug release profile and cost-effectiveness make biocompatible polymeric materials with hydrophilic nature, suitable in matrix systems [4]. Chance of drug crystallizing can be reduced in formulations and increased wettability [5]. Dispersing of active ingredients in an inert matrix in the solid state helps to attain improved dissolution rate, constant release of drugs [6]. Humic substances are moulded by secondary synthetic reactions, brown to black coloured series of comparatively high molecular weight. Its fractions obtained on the basis of solubility characteristics [7, 8]. In many countries traditional systems of medicine used it as a stimulating agent [9]. Humic substances are the main composition of shilajit an integral ingredient in Ayurveda and Siddha systems of medicine, in which fulvic acid act as its most bioactive component. This multicomponent natural occurring mineral substance originated in India and is used in safe dietary supplements. Wilson and co-workers reviewed the traditional use of shilajit and finds that it is used in twenty-four proprietary drugs. Sastric formulations also incorporate shilajit for enhancing the effectiveness of treatment [10].

\section{Humic substances-an overview}

Humic acid, fulvic acid and humins are the three core fractions of humic materials which are formed from amalgamation of biological and geochemical reactions. Thus, they differ in biomass stand as extracellular products of decomposition. When the strong-base extract is acidified humic acids are coagulated while fulvic acids remain soluble. General alkali extraction method is followed for recovery of humic and fulvic acids from sediments and soils. Hydrophilic nature of fulvic acid helps these to soluble under all $\mathrm{pH}$ conditions, XAD-4 resin is preferred for isolation. Humic acid demands higher $\mathrm{pH}$ condition for its solubility, XAD-8 resin is suitable for isolation. In contrast, humin is insoluble at all $\mathrm{pH}$. Molecular weight and the attached side groups are variable in all these fractions [11, 12]. This polymer compounds are highly resistant to further microbial degradation and varying combinations of organic molecules. Recognizable level of lignin-derived chemical moites are generally observed in terrestrial and freshwater humic substances, while marine humic substances are deficient in liginin moiety. Estuarine "sieve" makes marine and terrestrial humic substances differ in isotopic composition. Over the course of 80 million years, suitable geological conditions with exact combination of organic compounds makes humic substances are so special [13].

\section{Medicinal aspects of humic and fulvic acid}

Much information on the medicinal application of humic substances has been published. Chinese Materia Medica pharmacological compendium, dating back to the $15^{\text {th }}$ century Ming Dynasty is one of the important and earliest reports in this area [14]. Prior to 1978 in China, humic and fulvic acids had been used for the treating of a wide range of diseases and refered "Wujinsan", meaning "golden medicine". Because of the lack of clinical data, little research background of its therapeutic mechanism lead misconceptions remained as to therapeutic use of humic substances. Chinese drug administration approved the humic acid medicines [14]. Nontoxicity of humic and fulvic extract recommend for internal as well as external use [14, 15]. In 1761 Wallerius introduced the word [16] humic acid but systematically studied by Archard in 1786 [17]. Transcript from ayurvedic medicine strongly denotes to humic dating back over three thousand years [18]. Humic and fulvic acids are richness of minerals that can be easily assimilated in our body and stimulate various specific and non-specefic biological functions $[19,20]$. In natural medicine comprehensive database, humic substances prevail as a therapeutic agent with various bioactive potential. These are being recommended as dietary supplements and even in cosmetic products [21].

\section{Alleviate the common cold, fever and bronchitis}

In bronchitis treatment fulvic/humic acids drug combinations results better than conventional drug therapies [22]. Humic extracts are suggestively effective in hemorrhagic fever which removed clots, stopped bleeding and restored circulation [23].

\section{Anticancer nature of humic acids}

Humic extract can preventing tumors of the esophagus with $100 \%$ success rate. Also in case of thyroid tumors, humic substances injections were found to be highly effective (as high as 90\%). Fulvic acid enema is very usefull in the treatment of chronic ulcerous colon infections [24]. These substances as masks, poultices and bath therapy helps to improve skin conditions including ulcers and skin 
diseases. In fact, $90 \%$ success rate was reported in fulvic/humic mineral baths for ulcers, this effect was observed on internal ulcers as well [25]. Humic acid injection stopped thyroid tumor growth and reduced the size of tumor [24]. Anti-proliferative nature of humic substances in human cervical cancer cells were proved in studies by Hseu et al. [26]. The cytotoxic effect of humic acid on human breast adenocarcinoma cells was first investigated in studies by Aykac et al. [27]. Fulvic acid orginated from shilajit showed potential to induce the antiulcerogenic effect in albino rats [28].

\section{Antiviral property of humic substances}

Positive combat against foot-and-mouth disease by means of peat dust initiates the research on the antiviral effect of humic substances [28]. Activity against both naked and enveloped DNA viruses was already proved in preliminary in vitro studies with Coxsackie A9 virus, Influenza A virus, and Herpes simplex virus type 1 (HSV-1). Humic acid has an inhibition effect selectively against some of the human viruses immunodeficiency virus type 1(HIV-1) and types 2(HIV-2), cytomegalovirus (CMV) and Vaccinia virus $[29,30]$. Investigations revealed in most of the case early stage of virus replication is specifically inhibited by humic substances [31]. The effect of humic acid polymer on the early stage of herpesvirus replication has been confirmed by the results of animal experiments. Humic acid synthesised from hydroquinone was found to strongly inhibit HIV-1 [32].

Taken together results shows that humic substances are prophylactic promising candidates rather than therapeutic especially for the treatment of viral diseases.

\section{Anti-inflammatory effects and pro-inflammatory properties of humic substances}

Anti-inflammatory activity of humic substances was attributed to the various healing effect of peat therapy. Taugner (1963) [33] showed sodium humate significantly inhibits the development of various edemas. Membrane protective activities of humic acid type substances evidenced by inhibition in the lipoxygenase pathway of the arachidonic acid cascade, which is an integral part of the cell membrane. Synthetic low molecular weight humic substances 1500, which activate human neutrophil take part in pro-inflammatory activity [34]. Anti-inflammatory and antiallergic effects of fulvic acid extract from solubilized sludge are shown to reduce Bhexosaminidase and histamine release in immunoglobulin-Esensitized mast cells and basophil cells. Yamada et al. explained the activity of fulvic acid against immune disorders, specifically eczema. Fulvic acid can reduce the release of proinflammatory mediators and tumour necrosis factor alpha expression in differentiated human monocytes (U937). In primary human monocytes, after homocysteine stimulation, FvA is shown to reduce cyclooxygenase 2 and prostaglandinE2 secretion [35-37].

\section{Influence on blood coagulation}

Humic acid have an active role in antithrombotic defence mechanism by induced release of tissue-type plasminogen activator. It triggers plasminogen to plasmin, which splits insoluble fibrin to soluble fibrinogen degradation products [38]. Meantime humic acid was suppress the formation of fibrin monomers from fibrinogen through inhibition of thrombin, a coagulation enzyme [39, 40]. Fulvic acid oral medicine and injections are very effective in patients with acute upper gastroenterological bleeding with $95.6 \%$ success rate. Chinese government had special pharmaceutical preparation using humic and fulvic acids, developed for the treatment of hemorrhoid patients with support of clinical medical studies [40].

\section{Estrogenic activity}

Estrogenic effect of peat is mainly because of penetrating ability of humic acid to the skin. These outcomes may have also implications for the use of humic substances in dermatology and cosmetics [41].

\section{Anti-Anti-aging effects of humic substances}

Fulvic acid is serving to balance cell life by act as a powerful organic electrolyte. Along with this property fulvic and humic are one way to help replenish mineral levels in the body. Powerful anti-aging property of fulvic acid was proved in many hospital studies in China with elderly patients, ages 60-90, regained appetite, slept better, and became more energetic. This is the same as in hospital studies coming from India, that also able to help with symptoms of dementia [24, 42].

Antioxidant and immune boosting property of humic
substances

Humic substances reduce the effect of the consequence of free radicals in the body. Several immune-boosting properties of fulvic and humic acids have been identified in various studies, which may help protect against a variety of viruses. Some of the clinical studies revealed a positive response to treatment only after humic acid dosage, treatment for viral respiratory illness is clear evidence [43] Fulvic acid activate the immune system to kill bacteria, meantime it decrease proinflammatory markers. Immune modulating property of fulvic acid influence the redox state, and affect gut health [44]. Antioxidant property exhibited by humic substances and its fractions were evidenced in research work carried by Avvakumova et al. [45]. Antioxidant property of humic substances evidenced in invitro enzymatic luminescent bioassay and recommend humic substances as natural detoxifying agent [46]. Crbohydrate-derived fulvic acid can prevent the progression of the wound infection. In case of fulvic acid treated macrophages, intracellular signalling was increased and stimulate immune function $[47,48]$.

\section{Humic substances against diabetes mellitus}

Improper insulin signalling and attenuated glucose uptake are common symptoms in Type 2 Diabetes Mellitus. Fulvic acid extracted from shilajit, can increase superoxide dismutase activity in pancreatic beta cells. Studies carried out in diabetic rat's states effective reduction of hyperglycaemia [49-51].

\section{Humic substances in the drug delivery system}

In drug delivery system humic substances act as a carrier agent to enhance bioactivity. The solubility of the hepatoprotective agent, andrographolide (AGP) was enhanced in complexes with humic substances and boosted its hepatoprotective efficacy. The complexed AGP demonstrated improved solubility, dissolution. Dissolution and permeation across rat intestine is high in case of complexed AGP with better solubility [50]. Humic substance formulations also displayed better hepatoprotection against carbon tetrachlorideinduced liver toxicity than the free drug in rats [52]. On the other hand carbamazepine (CBZ) is a well-known anticonvulsant drug and has limited accessibility to the brain. Bioavailability and pharmacokinetic profiles of CBZ have been improved by complex formation with humic substances [52]. Mirza assessed the pharmacokinetic profile of CBZ and accessibility to the brain. These two complexing agents (humic and fulvic acid) have been compared on various indices such as their abilities to cause complex and enhance solubility, permeability and dissolution. This study also compared pharmacodynamic and biochemical profiles after oral administration of complexes [53]. Various pharmaceutical techniques such as freeze drying, physical mixture, kneading and solvent evaporation were generally selected for complex formation and evaluated for conformational analysis (molecular modeling). Preclinical study on rodents with CBZ-humic acid and CBZ-fulvic acid had yielded appreciable results in terms of their anticonvulsant and antioxidants activities [53].

The size of humic acids allows macromolecules to "roll" up to form microclusters or rings that at a certain $\mathrm{pH}$ (acidic) will precipitate, whilst fulvic acids are too small to go through a similar process and therefore remains in solution. The existence of functional groups like carboxylic and phenol groups allows humic and fulvic acids to form complexes with ions such as $\mathrm{Mg}^{2+}, \mathrm{Ca}^{2+}, \mathrm{Fe}^{2+}$ and $\mathrm{Fe}^{3+}$. Functional groups existences and arrangement in humic substances enable the formation of chelate complexes. The humic chelate complexes formation is an important aspect of the biological role of humic acids in regulating bioavailability of metal ions [54]. Elemental characterization of humic fractions on an atomic basis by Helal and coworkers shows that fulvic acids have $22 \%$ more hydrogen to carbon atoms, $21 \%$ more oxygen than carbon and $14 \%$ more carboxylic acid groups than humic acids. This implies that fulvic acids contain more functional groups of an acidic nature, predominantly $\mathrm{COOH}$ meantime 
it is more reacting with cations [55]. Yamauchi and co-workers 1984 states, total acidity of humic acids are considerably lower than the fulvic acids [56]. Atomic based elemental characterization of humic fractions carried by Helal et al. explained that fulvic acids have $22 \%$ more hydrogen to carbon atoms, $21 \%$ more oxygen than carbon and $14 \%$ more carboxylic acid groups than humic acids [55]. Low aqueous solubility rate of furosemide was overcome by complex formation with fulvic and humic acid, the better understanding of the structure behaviour improve the aqueous solubility, dissolution rate, and permeability of furosemide, finally boost the in-vivo diuretic effect on male wistar rat. Various spectroscopical and microscopic examinations approve the amorphous inclusion complex formation of the drug with humic substances [57]. Bioavailability enhancer potential of humic substances, extracted from shilajit, evidenced in study carried out in ketoconazole, which dissolution rate were significantly enhanced in complex with fulvic and humic acid due to its micellization nature [58, 59]. In vitro and in vivo studies using poorly water-soluble silymarin strongly recommend fulvic acid as a watersoluble carrier. Binary system made between silymarin and fulvic acid revealed linear increase in drug solubility with an increase in carrier concentration [60]. Fulvic acid and aspirin formulation helps to overcome problem of stability and bioavailability of aspirin. Aspirin formulation with fulvic acid helps to overcome problem of stability and bioavailability of aspirin and gives better results of antiulcerogenic action as compared to pure drug [61]. Experimental data from the studies of Khil'ko and Semenova indicates interactions between humic acid salts and the drug preparations from papaverine hydrochloride, benzohexonium and B-group vitamins. Drug interaction with natural macromolecule mainly depends on the charges and peculiarities of molecular structure [62].

\section{Future prospects of humic substance in pharmaceutical research}

The researches on humic substances still have great relevance in drug formulation and drug delivery system. Based on the collective indication of the biochemical and molecular effects of humic substances may make them robust candidates for cancer therapy. However, despite the relatively strong evidence for a beneficial effect of these compounds on cancer treatment, these compounds have received comparably little attention with regards to their potential role in cancer etiology. While experimental research will always be essential, in the years to come, molecular simulations of HS are expected to become increasingly useful, particularly for providing a more detailed understanding of experimental observations, for guiding the design of new experiments, and for predicting properties and phenomena at the molecular scale.

\section{AUTHORS CONTRIBUTIONS}

All the author have contributed equally

\section{CONFLICTS OF INTERESTS}

Declared none

\section{REFERENCES}

1. Mirza MA, Agarwal SP, Rahman MA, Rauf A, Ahmad N, Alam A, Iqbal Z. Role of humic acid on oral drug delivery of an antiepileptic drug. Drug Dev Ind Pharm 2011;37:310-9.

2. Manna S, Kollabathula J. Formulation and evaluation of ibuprofen controlled release matrix tablets using its solid dispersion. Int J Appl Pharm 2019;11. DOI:https://doi.org/10.22159/ijap.2019v11i2.30503

3. Kulkarni V, Patil BS, Hariprasnna RC, Borgaonkar PA, Hogada MG, Rabbani G. Formulation and development of fast dissolving meloxicam tablets by solid dispersion technique: for the effective treatment of dental pain. Int J Curr Pharma Res 2010;2:82-5.

4. Syed IA, Mangamoori LN, Rao YM. Formulation and characterization of matrix and triple-layer matrixtablets for oral controlled drug delivery. Int J Pharm Pharm Sci 2010;2:623.

5. Shukla M, Rathore P, Jain A, Nayak S. Enhanced solubility study of glipizide using different solubilization techniques. Int J Pharm Pharm Sci 2010;2:46-8.

6. Kumar GA, Choudhary RK, Chaitanya CH. Enhancement of solubility and dissolution rate of irbesartan by solid dispersion technique. Asian J Pharm Clin Res 2011;4:36-40.
7. Stevenson F, Humus chemistry: genesis, composition, reactions. $2^{\text {nd }}$ ed. Wiley and Sons, New York; 1994.

8. Aiken GR. Humic substances in soil, sediment, and water: geochemistry, isolation, and characterization. WileyInterscience, New York; 1985.

9. Acharya SB, Frotan MH, Goel RK, Tripathi SK, Das PK. Pharmacological actions of shilajit. Indian J Exp Biol 1988;26:775-7.

10. Wilson E, Rajamanickam GV, Dubey GP, Klose P, Musial F, Saha FJ, et al. Review on shilajit used in traditional Indian medicine. J Ethnopharmacol 2011;136:1-9.

11. Ishiwatari R. Macromolecular material (humic substance) in the water column and sediments. Mar Chem 1992;39:151-66.

12. Saito B, Seckler MM. Alkaline extraction of humic substances from peat applied to organic-mineral fertilizer production. Braz J Chem Eng 2014;31:675-82.

13. Millero FJ, Sohn ML. Composition of the major components of seawater. Chemical Oceanography. CRC Press Inc. United Stated of America; 1992. p. 59-113.

14. Yuan S. Application of fulvic acid and its derivatives in the fields of agriculture and medicine $1^{\text {st }}$ ed; 1993.

15. Klocking R, Helbig B. Medical aspects and applications of humic substances. Biopolymers for medical and pharmaceutical applications. WILEY-VCH Verlag GmbH and C. KGaA. Weinheim; 2005. p. 3-16.

16. Wallerius JG, Gyllenborg GA. Agriculturae fundamenta chemical; 1761.

17. Archard FW. Crell's Chemical Analysis 2,391. Cited in Stevenson, FJ Humus Chemistry; 1982.

18. Carrasco Gallardo C, Guzman L, Maccioni RB. Shilajit: a natural phytocomplex with potential procognitive activity. Int J Alzheimer's Dis 2012. http://dx.doi.org/10.1155/2012/ 674142

19. Marin Hum. Soil mineral depletion. In: Optimum nutrition, Autumn; 2006.

20. Schnitzer M. Binding of humic substances by soil mineral colloids. In Interactions of soil minerals with natural organics and microbes. SSSA Special Publication 1986;17:77-101.

21. Mirza MA. Future of humic substances as pharmaceutical excipient. Pharma Sci Anal Res J 2018;1:180004.

22. Cao S. Fulvic acid information asthma and lung infections on the rise in all age groups. Ann Allergy Asthma Immunol 2000;84:227-33.

23. Yinzhang C. The Editors of Encyclopaedia Britannica, Humic Acid; 1991.

24. Yuan, Shenyuan. Fulvic Acid, 4 1988. In: Application of fulvic acid and its derivatives in the fields of agriculture and medicine, $1^{\text {st }}$ ed; 1993.

25. Pant K, Gupta A, Gupta P, Ashraf A, Yadav A, Venugopal S. Antiproliferative and anticancer properties of fulvic acid on hepatic cancer cells. J Clin Exp Hepatol 2015;5:S2.

26. Hseu YC, Chen SC, Chen YL, Chen JY, Lee ML, Lu FJ, et al. Humic acid-induced genotoxicity in human peripheral blood lymphocytes using comet and sister chromatid exchange assay. J Hazard Mater 2008;153:784-91.

27. Aykac A, Becer E, Okcanoglu TB, Guvenir M, Suer K, Vatansever $\mathrm{S}$. The cytotoxic effects of humic acid on human breast cancer cells. In: Multidisciplinary digital publishing institute proceedings; 2018;2:1565.

28. Ghosal S, Singh SK, Kumar Y, Srivastava R, Goel RK, Dey R, et al. Anti-ulcerogenic activity of fulvic acids and 4'-methoxy-6-carbomethoxybiphenyl isolated from shilajit. Phytother Res 1988;2:187-91.

29. Klocking R, Sprossig M. Antiviral properties of humic acids. Cell Mol Life Sci 1972;28:607-8.

30. Schols D, Wutzler P, Klöcking R, Helbig B, De EC. Selective inhibitory activity of polyhydroxycarboxylates derived from phenolic compounds against human immunodeficiency virus replication. J Acquir Immune Defic Syndr 1991;4:677-85.

31. Neyts J, Snoeck R, Wutzler P, Cushman M, Klöcking R, Helbig B, et al. Poly (hydroxy) carboxylates as selective inhibitors of Cytomegalovirus and Herpes simplex virus replication. Antivir Chem Chemother 1992;3:215-22.

32. Schneider J, Weis R, Maenner C, Kary B, Werner A, Stubert BJ, et al. Inhibition of HIV-1 in cell culture by synthetic humate 
analogues derived from hydroquinone: mechanism of inhibition. Virology 1996;218:389-95.

33. Taugner B. Experimental studies in animals on a sodium humate salicylic acid bath. Arzneimittel Forschung 1963; 13:329-33.

34. Schewe C, Klöcking R, Helbig B, Schewe T. Lipoxygenaseinhibitory action of antiviral polymeric oxidation products of polyphenols. Biomed Biochim Acta 1991;50:299-305.

35. Junek R, Morrow R, Schoenherr JI, Schubert R, Kallmeyer R, Phull S, et al. Bimodal effect of humic acids on the LPS-induced TNF- $\alpha$ release from differentiated U937 cells. Phytomedicine 2009;16:470-6.

36. Chien SJ, Chen TC, Kuo HC, Chen CN, Chang SF. Fulvic acid attenuates homocysteine-induced cyclooxygenase- 2 expression in human monocytes. BMC Complement Altern Med 2015;15:61

37. Yamada $\mathrm{P}$, Isoda $\mathrm{H}, \mathrm{Han} \mathrm{JK}$, Talorete TP, Yamaguchi T, Abe Y. Inhibitory effect of fulvic acid extracted from canadian sphagnum peat on chemical mediator release by RBL-2H3 and KU812 cells. Biosci Biotechnol Biochem 2007;71:1294-305.

38. Klocking HP, Hoffmann A, Fareed J. Influence of hyper sulfatedlactobionic acid amides on tissue plasminogen activator release. In: Seminars in thrombosis and hemostasis, Thieme Medical Publishers, Inc; 1991;17:379-84.

39. Klöcking R. Humic substances as potential therapeutics. Senesi N, Miano TM. (eds). Amsterdam, Elsevier; 1994.

40. Klöcking HP, Helbig B, Klocking R. Antithrombin activity of synthetic humic acid-like polymers derived from o-diphenolic starting compounds. Trombosis Haemostasis Supp; 1999. p. 299-300.

41. Klocking R, Helbig B. Medical aspects and applications of humic substances. In Biopolymers for medical and pharmaceutical applications. WILEY-VCH Verlag Gmb H, C KGaA Weinheim; 2005. p. 3-16.

42. Jackson WR. Humic, fulvic and microbial balance: organic soil conditioning. Evergreen, Colorado: Jackson Research Center; 1993.

43. Lu FJ, Tseng SN, Li ML, Shih SR. In vitro anti-influenza virus activity of synthetic humate analogues derived from protocatechuic acid. Arch Virol 2002;147:273-84.

44. Khilko SL, Efimova IV, Smirnova OV. Antioxidant properties of humic acids from brown coal. Solid Fuel Chem 2011;45:367-71.

45. Avvakumova NP, Gerchikov AY, Khairullina VR, Zhdanova AV. Antioxidant properties of humic substances isolated from peloids. Pharm Chem J 2011;45:192.

46. Tarasova AS, Stom DI, Kudryasheva NS. Antioxidant activity of humic substances via bioluminescent monitoring in vitro. Environ Monit Assess 2015;187:89.

47. Zhao Y, Paderu P, Delmas G, Dolgov E, Lee MH, Senter M, et al. Carbohydrate-derived fulvic acid is a highly promising topical agent to enhance healing of wounds infected with drugresistant pathogens. J Trauma Acute Care Surg 2015;79:S121-9.

48. Gandy JJ, Snyman JR, Van Rensburg CE. Randomized, parallelgroup, double-blind, controlled study to evaluate the efficacy and safety of carbohydrate-derived fulvic acid in topical treatment of eczema. Clin Cosmet Investig Dermatol 2011; $4: 145$.

49. Martin BC, Warram JH, Krolewski AS, Soeldner JS, Kahn CR, Bergman RN. Role of glucose and insulin resistance in the development of type 2 diabetes mellitus: results of a 25 -year follow-up study. Lancet 1992;340:925-9.

50. Donath MY, Shoelson SE. Type 2 diabetes as an inflammatory disease. Nat Rev Immunol 2011;11:98.

51. Winkler J, Ghosh S. Therapeutic potential of fulvic acid in chronic inflammatory diseases and diabetes. J Diabetes Res 2018. https://doi.org/10.1155/2018/5391014

52. Vetvicka V, Garcia Mina JM, Proctor M, Yvin JC. Humic acid and glucan: protection against liver injury induced by carbon tetrachloride. J Med Food 2015;18:572-7.

53. Mirza MA, Ahmad N, Agarwal SP, Mahmood D, Anwer MK, Iqbal Z. Comparative evaluation of humic substances in oral drug delivery. Res Pharm Sci 2011;1:16-26.

54. Vermeer AW. Interactions between humic acid and hematite and their effects on metal ion speciation. Doctoral Dissertation; 1996. p. 1-199.

55. Helal AA, Murad GA, Helal AA. Characterization of different humic materials by various analytical techniques. Arab J Chem 2011;4:51-4.

56. Yamauchi M, Katayama S, Todoroki T, Watanable T. Total synthesis of fulvic acid. J Chem Soc Chem Comm 1984;23:1565-6.

57. Agarwal SP, Anwer MK, Aqil M. Complexation of furosemide with fulvic acid extracted from shilajit: a novel approach. Drug Dev Ind Pharm 2008;34:506-11.

58. Agarwal SP, Ansari SH, Karmarkar RR. Enhancement of the dissolution rate of ketoconazole through a novel complexation with fulvic acid extracted from shilajit. Asian J Chem 2008;20:879.

59. Agarwal SP, Ansari SH, Karmarkar RR. Enhancement of the dissolution rate of ketoconazole through a novel complexation with humic acid extracted from shilajit. Asian J Chem 2008;20:380

60. Javed S, Kohli K, Ahsan W. Solubility and dissolution enhancement of Silymarin with the fulvic acid carrier. Int J Drug Dev Res 2016;8:9-14.

61. Anwer M, Ahmed M, Ansari M, Khan T. Inclusion complex of solid state aspirin with fulvic acid: dissolution, permeability, stability and preliminary pharmacological studies. J Biol Sci 2013;13:203-312.

62. Khilko SL, Semenova RG. Interaction of humic acid salts with drug preparations. Solid Fuel Chem 2016;50:390-4. 